\title{
Does Farmland Size Affect the Collective Action in Rural Areas? An Empirical Study on the Public Irrigation System in China
}

\author{
Liangzhen Zang ${ }^{1, *}$, Yiqing $\mathrm{Su}^{2}$ \\ ${ }^{1}$ Institute of Agricultural Economics and Development, Chinese Academy of Agricultural Sciences, 100081 Beijing, China \\ ${ }^{2}$ School of Public Policy and Management, Guangxi University, 530004 Nanning, China
}

\begin{abstract}
Since smallholders accounted for a high proportion of $98.1 \%$ among the 207 million agricultural business households across China, it is particularly important to study the impact of farmland size on the provision of public goods attached to the public sector industries from the perspective of the irrigation collective action in rural areas. Based on the survey data of 283 villages in China, this paper finds that the farmland size has a positive impact on irrigation collective action, although the average of per capita farmland area is only 0.214 hectares in each household of China. Therefore, it is necessary to promote the farmland scale operation by land circulation, so as to improve the ability of collective action and the development of public sector industries in rural areas of China.
\end{abstract}

\section{Introduction}

Since the reform and opening up, China's agriculture and rural areas have undergone earth-shaking changes. The provision of public goods, however, is faced with increasingly severe problems, such as the deterioration of rural human settlements, the degradation of ecoenvironment, and the insufficient supply of public services, so that it becomes difficult to maintain rural collective actions [1]. That is because it is inextricably linked to China's national conditions as "a large country with a large population of smallholders". According to the Third National Agricultural Census Data Bulletin, as of 2016, among the 207 million agricultural business households across China, smallholders accounted for a high proportion of $98.1 \%$. Smallholders serve as the most fundamental unit of agricultural production in China, and also the most fundamental force that plays a major role in the governance of rural public affairs in China.

The key to achieving the goal of "effective governance of rural public affairs" is to effectively promote peasant households to participate in the governance of rural public affairs, especially to solve the current problem of insufficient supply of rural public goods. Therefore, how to effectively encourage peasant households' to participate in the supply of rural public goods has become the top priority in solving the tough problem of insufficient supply of rural public goods and imbalance between supply and demand.

Common-pool resources including collective irrigation facilities are an important part for the governance of rural public affairs. It is significant for realizing effective rural governance to clarify the collective actions logic of peasant households participating in the governance of this type of public affairs. The farmland irrigation facilities are the typical common-pool resources, because the construction and maintenance of irrigation facilities directly reflect the capacity of taking collective actions in rural areas. Therefore, it is important to find the impact of farmland resources on the supply of common-pool resources especially for the irrigation facilities because of such "a large country with a large population of smallholders".

\section{Literature Review}

The analysis of the status quo of the capacity of rural irrigation collective actions is an important basis for the analysis of the influencing factors and mechanism underlying the supply of common-pool resources. At present, many Chinese scholars have conducted researches on the status quo of rural irrigation collective actions in China based on big data, and the researches showed that the current capacity of rural irrigation collective actions in China is rather low. Therefore, some scholars analyzed the reasons for the difficulty in forming rural irrigation collective actions in China from qualitative perspectives.

For example, Ding (2012) studied the problems in the collective irrigation actions in Wangping Village, Shayang, Hubei, and found out that the reasons for the difficulty in forming irrigation collective actions included the disintegration of village-level organization, the "atomization" among villagers and the difficulty in implementing the system of "specific negotiation for each case", and the weak village-level organizational capacity [2]. Wu (2017) adopted game theory to study farmland water conservancy cooperation among farmers, and concluded that the spontaneous cooperation among

\footnotetext{
* Corresponding author: zangliangzhen@ $@$ caas.cn
} 
farmers in farmland water conservancy may not be achieved, mainly due to the weakening of the rural community capacity composed of integration, participation and execution capacities, which fails to effectively resolve the participation costs, integration costs and execution costs; specifically, the reason for the weakening of community capacity is mainly the atomization of rural society and the virtualization of rural grassroots organizations [3].

In addition to the above qualitative analysis, most scholars mainly adopt quantitative methods to analyze the influencing factors of rural collective actions for irrigation. In general, current researches mainly use field surveys to obtain relevant data, and on this basis adopts regression analysis, factor analysis and other methods to analyze the extent to which each element affects rural collective actions for irrigation. From the extant literatures, some scholars analyzed all the relevant elements that affect the rural collective actions for irrigation, and proposed the most important influencing factors.

For example, Cai (2015) pointed out that the education level of farmers and the initiative to resolve water disputes were the main factors that promote farmers to cooperate for irrigation [4]. Cai (2014) argued that there was a certain positive correlation between the social trust and income level of farmers and the supply of rural irrigation facilities [5]. Cai (2017) held that the impact from village size and income inequality on rural collective actions for irrigation both presented "inverted U-shaped" characteristics [6]. They also pointed out that there was an inverted U-shaped relationship between endowment heterogeneity and collective actions, and moderate endowment heterogeneity contributed to the success of collective actions; social heterogeneity had a negative effect on collective actions; and the gender of community members also had a certain impact on collective actions. Researches by Ke (2015) revealed that age, education level, proportion of agricultural income, evaluation of facility water yield, and current management and protection are the main factors affecting rural collective actions for irrigation [7]. Wang (2014) believed that farmers' cognition degree in terms of water conservancy had the greatest positive effect on rural collective actions for irrigation, followed by the expected rate of return, while risk preference and basic characteristics of peasant households had little effect [8].

In addition to the above researches, some scholars also analyzed specific influencing factors. For example, Ding (2013) analyzed the impact of economic heterogeneity, social and cultural heterogeneity, intergenerational gender heterogeneity, and political heterogeneity on rural collective actions for irrigation, using survey data from 400 peasant households in Hubei Province [9]. It was indicated that social and cultural heterogeneity and political heterogeneity were important factors that affect rural collective actions for irrigation, while economic heterogeneity and intergenerational gender heterogeneity had little effect. Cai (2017) used the data of 1,440 peasant households in the three provinces of Ningxia Hui Autonomous Region, Shaanxi, and Henan to analyze the impact of the relationship network on farmers' participation in rural collective actions (investment in the construction of small-scale farmland water conservancy) [10]. In terms of relationship network evaluation, the "number of relatives and friends owned by the household" is used as an index for evaluating the relationship network, the "number of friends owned by the household" is used as a weak index for evaluating the relationship network, and the "number of relatives owned by the household" is used as a strong index for evaluating the relationship network. The research showed that the relationship network could promote the success of rural collective actions for irrigation. Miao (2014) studied the impact of social capital on rural collective actions for irrigation (cooperation on small-scale water conservancy facilities), and argued that the trust dimension, participation dimension, and network dimension were the main factors driving farmers to participate in rural collective actions for irrigation, and the prestige dimension reduced farmers' participation; in addition, the multi-dimensional heterogeneity of social capital would also lead to uncertainty in the results of collective actions [11]. Xu (2015) studied the impact of social capital on rural collective actions for irrigation (willingness for irrigation management reform), and held that social trust and social network had positive effects on the development of rural collective actions for irrigation, but the impact from social norms was not obvious [12].

\section{Framework, Variables and Method}

\subsection{Framework}

According to the Institutional Analysis and Development framework, the external factors affecting rural collective action can be summarized into three aspects: natural material conditions, economic and social attributes and general institutional rules. These three kinds of external variables constantly influence the action arena constituted by actors and action scenarios, and form outputs through interaction, which then feedback and influence external factors, and finally form a complete action system. The characteristics of small-scale farmer households, such as insufficient resource endowment, can be summed up as one of the three types of external variables of collective action, and they are intersecting. In general, characteristics such as insufficient per capita resources can be classified into different conceptual categories in the external factors of Institutional Analysis and Development framework, and they themselves also affect rural collective action through a variety of intermediary mechanisms.

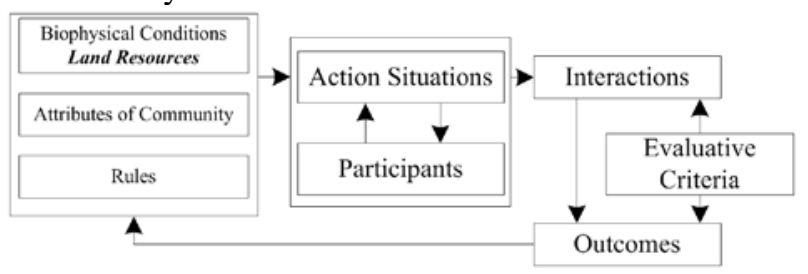

Fig. 1. Framework 


\subsection{Variables}

There are many indicators to measure the rural irrigation collective action, and the research angle is also different. For example, from the perspective of farmers' current behaviors, these indicators include farmers' participation in the maintenance of rural irrigation facilities, investment status, cost sharing status and so on. From the perspective of future behavior, these indicators include the willingness to reform the collective water system, the willingness to pay for water in the future, and the willingness to invest in facility construction. However, since this part studies the rural irrigation collective action from the village level, the indicator of "how the village collective irrigation facilities are maintained in the past three years" is selected as the village-level indicator to measure the rural irrigation collective action in combination with the specific questionnaire in this study. In the process of specific investigation, as the questionnaire was set up using Likert scale, ordered Probit model will be used for analysis. In terms of the endowment of land resources, this study takes the area of arable land resources per capita of the population in the village as a specific measurement indicator.

In addition to the above indicators, we also select other variables as control variables, including several variables, such as the terrain of the village, the water resources of the village, the distance between the village and the city, whether the village is dominated by planting industry, whether it is a poor village, whether there are punishment measures for stealing water at the village level, the failure of village governance, whether there is a water association in the village, and government fund support, etc.

\subsection{Method}

The data, covering 283 villages across China, used in this study are mainly from the survey data of China Institute for Rural Studies, Tsinghua University in 2017. The following econometric model is constructed:

$$
Y_{i}^{*}=\beta X+\varepsilon, \quad i=1,2, \quad \cdots, 5
$$

The evaluation indicators of rural irrigation collective action can be grouped into five different levels. Therefore, its essence is a sorting and selection problem. Therefore, this study adopts the ordered Probit model to analyze the influence of land size on farmers' participation in irrigation collective action, with the specific formula as follows:

$$
Y_{i}=\left\{\begin{array}{c}
1, \text { if } Y_{i}^{*} \leq \alpha_{1} \\
2, \text { if } \alpha_{1}<Y_{i}^{*} \leq \alpha_{2} \\
\ldots \ldots \ldots \\
5, \text { if } Y_{i}^{*}>\alpha_{4}
\end{array}\right.
$$

\section{Results}

\subsection{Descriptive statistical analysis}

This study uses Stata software for analysis. Firstly, descriptive analysis was performed on the selected dependent variables, core independent variables and spatial variables. In terms of collective actions on rural irrigation, the average value of the index of "how the village collective irrigation facilities are maintained in the past three years" is 3.739 , that is, the current maintenance status of collective irrigation facilities in most villages is at an average level. The maximum per capita arable land resource area is 1.609 hectares, the minimum is 0.006 hectares, and the average is only 0.214 hectares. It indicates that the per capita arable land resource area of the surveyed villages is small.

\subsection{Results of Econometric Analysis}

The following table shows the results of the econometric analysis using the Stata software. The values in the table are the coefficient values of the regression results. $* * *$ means that the results are significant at the level of $1 \%$, ** means that the results are significant at the level of $5 \%$, and $*$ means that the results are significant at the level of $10 \%$. Model 1 is the measurement result without adding the control variable of each province, and Model 2 is the measurement result with adding the control variable of each province.

The table shows that the core independent variable of arable land resource endowment presents a positive effect in both models, and it is significant at the level of $10 \%$. The measurement results show that the variable of arable land resource endowment has a significant positive promoting effect on the formation of rural irrigation collective actions, that is, the larger the per capita area of arable land resources is, the stronger the farmer's participation in rural irrigation collective actions will be, and the better the maintenance effect of the collective irrigation facilities in the whole village will be. This fully indicates that the larger the area of arable land resources held by the farmers in a certain region (village), the more the farmers in the whole village expect to be able to rely on agriculture for living. Therefore, in order to maintain the smooth progress of agricultural production activities, farmers are more inclined to maintain the rural public goods (irrigation facilities) through collective action, so as to reduce the high cost of agricultural production through collective action, and thus contribute to the success of rural irrigation collective action.

Table 1. Results of Econometric Analysis

\begin{tabular}{lcc}
\hline \multicolumn{1}{c}{ Variables } & Model 1 & Model 2 \\
\hline $\begin{array}{l}\text { Core independent variable } \\
\quad \text { Land size }\end{array}$ & $0.780^{*}$ & $0.772^{*}$ \\
$\begin{array}{l}\text { Control variables } \\
\quad \text { Village terrain }\end{array}$ & 0.125 & $0.301^{*}$
\end{tabular}




\begin{tabular}{|c|c|c|}
\hline Village water resources & $-0.383 * *$ & -0.181 \\
\hline $\begin{array}{l}\text { Distance between the } \\
\text { village and the city }\end{array}$ & $-0.146^{*}$ & -0.064 \\
\hline $\begin{array}{l}\text { Whether the village is } \\
\text { dominated by planting } \\
\text { industry }\end{array}$ & -0.259 & -0.075 \\
\hline Whether it is a poor village & -0.281 & $-0.351 *$ \\
\hline $\begin{array}{l}\text { Whether there are } \\
\text { punishment measures }\end{array}$ & -0.201 & -0.086 \\
\hline $\begin{array}{l}\text { Failure of village } \\
\text { governance }\end{array}$ & $-0.111 *$ & -0.082 \\
\hline $\begin{array}{l}\text { Whether there is a water } \\
\text { association }\end{array}$ & 0.260 & 0.359 \\
\hline Government fund support & -0.091 & 0.013 \\
\hline Province & No & yes \\
\hline Sample & 283 & 283 \\
\hline Chi2 & 22.23 & 77.95 \\
\hline$r 2 p$ & 0.0308 & 0.1081 \\
\hline
\end{tabular}

\section{Discussion}

This study uses Stata software for analysis. Firstly, descriptive analysis was performed on the selected dependent variables, core independent variables and spatial variables. In terms of collective actions on rural irrigation, the average value of the index of "how the village collective irrigation facilities are maintained in the past three years" is 3.739, that is, the current maintenance status of collective irrigation facilities in most villages is at an average level.

The above research results are consistent with the research results of other scholars in China. For example, Mao (2016) used the data from 3,552 surveys of farmers in 21 provinces to find that the larger the contracted arable land area, the stronger the willingness of farmers to participate in the construction and management of small irrigation and water conservancy [13]. Yuan analyzed 192 sample farmers in Henan Province and found that the larger the area of arable land owned by farmers, the stronger the degree of participating in the management and protection of small irrigation and water conservancy facilities [14]. It can be seen that although per capita arable land resources are relatively small in rural areas of China, the higher the degree of arable land resource endowment, the stronger the degree and willingness of farmers to participate in rural irrigation collective actions. Farmers will maintain sustainable agricultural production through collective cooperation, and thus improve the income level of farmers by reducing the maintenance cost of irrigation facilities. Therefore, from the perspective of the whole village, in terms of rural irrigation collective action, the stronger the arable land resource endowment in the village, the higher the collective action capacity of the whole village on rural irrigation.

The reason that land size plays a positive impact on irrigation collective action could be summarized as follows: Firstly, the smaller plot area reduces the economy of scale. Under normal circumstances, the smaller the plot area, the higher the production cost per unit of agricultural products, and the lower the marginal output elasticity of input factors in the agricultural production process, which will greatly weaken the economy of scale for agricultural production. Secondly, the smaller plot area leads to the abandonment of arable land. In the case of holding multiple plots, some farmers may choose to discard some of the smaller ones due to their lower economy of scale, thus the efficiency of land use will seriously decrease. Thirdly, extant researches demonstrate that the smaller plots are usually lower in market transaction prices.

\section{Conclusion}

This paper mainly discusses the impact of arable land resource endowment on rural irrigation collective action from the perspective of village level. The ordered Probit model was used to measure the impact of arable land resource endowment on rural irrigation collective action by taking "how the village collective irrigation facilities are maintained in the past three years" and "the area of arable land resources per capita" as the important variables. The results show that although the per capita resources in rural areas of China are small, the higher the degree of arable land resource endowment, the better the performance of the collective action of irrigation in the whole countryside. The research conclusions obtained from the macro perspective in this paper, on the one hand, lay a good cognitive foundation for the follow-up research on the micro level; on the other hand, are in line with the research results of current scholars to a large extent, indicating that the data used in this study have a certain credibility, and provide better data support for the follow-up research.

\section{References}

1. Y. Wang. Bulletin of Chinese Academy of Sciences 32, 10 (2017).

2. J. Ding, G. Huang. Rural Economy 8 (2012).

3. Q. Wu, H. Lin. China Rural Survey 6 (2017).

4. J. Cai, Y. Lin. Bulletin of Chinese Academy of Sciences 5 (2015).

5. R. Cai, S. Cai. Economy Review 1 (2014).

6. Q. Cai, Y. Zhu. Journal of Nanjing Agricultural University (Social Sciences Edition) 1 (2017).

7. X. Ke, X. Huang. Journal of Hunan Agricultural University (Social Sciences) 3 (2015).

8. X. Wang, Q. Lu. Journal of Huazhong Agricultural University (Social Sciences Edition) 7 (2014).

9. D. Ding, F. Zheng. China Population, Resource and Environment 9 (2013).

10. Q. Cai, Y. Zhu. Journal of Nanjing Agricultural University (Social Sciences Edition) 1 (2017).

11. S. Miao. China Population, Resource and Environment 12 (2014).

12. L. Xu, D. Luo, A. Liu. Resources Sciences 6 (2015). 
13. M. Mao. China Population, Resource and Environment 12 (2016).

14. J. Yuan, W. Du. Journal of Economics of Water Resources 3 (2016). 